\title{
Implementasi Pembelajaran Terpadu di SD Negeri Sarwiru Kabupaten Sumedang
}

\section{Jaja Sukma Raharja" ${ }^{* 1}$, Adela Rizki Nur Atikah², Mega Adinda Eka Laksana ${ }^{3}$, Wanty Cahyanti, Ani Nur Aeni ${ }^{5}$}

\author{
1,2,3,4,5 Pendidikan Guru Sekolah Dasar Universitas Pendidikan Indonesia, Indonesia \\ Email: ${ }^{1}$ sukmajaja@upi.edu, ${ }^{2}$ adelarizki10@upi.edu, ${ }^{3}$ megaadinda@upi.edu, ${ }^{4}$ wantycahyanti@upi.edu, \\ 5 aninuraeni@upi.edu
}

\begin{abstract}
Abstrak
Pembelajaran terpadu sudah diterapkan di SDN Sarwiru yang ada di kabupaten Sumedang. Dalam penelitian ini bahwa SDN sarwiru memadukan antara 1 mata pelajaran dengan mata pelajaran yang lain, karena kita ketahui bahawa pembelajaran terpadu yaitu gabungan antara mata pelajaran 1 dengan yang lainnya. SDN Sarwiru juga terdapat kendala yang di alaminya, seperti mencari materi pelajaran 1 dengan mata pelajaran yg lain dalam satu tema dan kesulitan dalam merancang pembelajaran tematik yang sangat padu. Oleh karena itu penelitian ini sangat bermanfaat bagi penulis dan pembaca untuk mengetahui penerapan pembelajaran terpadu yg ada salah satunya di kabupaten Sumedang. Penelitian ini bertujuan untuk mengimplementasi Pembelajaran Terpadu Di SD Negeri Sarwiru Kabupaten Sumedang. Implementasi pembelajaran terpadu tersebut untuk mengetahui Implementasi sistem pembelajaran terpadu di SD negeri Sarwiru meliputi desain pembelajaran, proses belajar mengajar dan evaluasi pembelajaran dan mengetahui kesulitan yang dialami dalam mengimpementaikan Pembelajaraan Terpadu. Penelitian ini menggunakan jenis penelitian kualitatif menggunakan metode penelitian deskriptif. Penelitian dilaksanakan di SD Negeri Sarwiru. Dengan melibatkan dua orang guru kelas untuk di wawancara. Teknik wawancara dilakukan melalui media sosial WhatsApp. Hasil Penelitian menunjukkan bahwa guru di SD Negeri Sarwiru sebagian besar sudah mengetahui mengenai pembelajaran terpadu. Dengan demikian, implementasi pembelajaran terpadu di SD Negeri Sarwiru ini layak untuk dijadikan bahan penelitian kelompok kami.
\end{abstract}

Kata kunci: implementasi, pembelajaran terpadu, sekolah dasar

\section{Implementation of Integrated Learning at SD Negeri Sarwiru, Sumedang}

\begin{abstract}
Integrated learning has been implemented at SDN Sarwiru in the Sumedang district. In this study, SDN Sarwiru combines 1 subject with other subjects, because we know that integrated learning is a combination of 1 subject with others. SDN Sarwiru also experienced obstacles, such as finding subject matter 1 with other subjects in one theme and difficulties in designing very coherent thematic learning. Therefore, this research is very useful for writers and readers to find out the implementation of integrated learning, one of which is in the Sumedang district. This study aims to implement Integrated Learning at SD Negeri Sarwiru, Sumedang Regency. The implementation of integrated learning is to find out the implementation of the integrated learning system at $S D$ Negeri Sarwiru including learning design, teaching and learning process, and learning evaluation, and to find out the difficulties experienced in implementing Integrated Learning. This study uses qualitative research using descriptive research methods. The research was conducted in Sarwiru State Elementary School. By involving two classroom teachers to be interviewed. The interview technique was carried out through WhatsApp social media. The results showed that most of the teachers at SD Negeri Sarwiru already knew about integrated learning. Thus, the implementation of integrated learning at SD Negeri Sarwiru is worthy of being used as research material for our group.
\end{abstract}

Keywords: implementation, integrated learning, primary school

\section{PENDAHULUAN}

Di masa arus modernisasi dan informasinya semakin mudah didapatkan, mengharap peran pendidikan menjadi semakin berkualitas. Commission on Education for Twenty-First Century dalam [1] mengemukakan bahwa UNESCO telah merekomendasikan empat pilar pendidikan (the four pillars of education) untuk 
memasuki era global, yaitu; “1) Learning to know, yang berarti belajar untuk mendapatkan pengetahuan dan melakukan pembelajaran selanjutnya. 2) Learning to do, yaitu belajar untuk memperoleh kemampuan dasar yang berhubungan dengan situasi dan tim kerja yang berbeda-beda. 3) Learning to live together, yaitu belajar agar mampu mengapresiasikan dan mengamalkan kondisi saling ketergantungan, keanekaragaman, saling memahami dan perdamaian inter dan antar bangsa. 4) Learning to be, yaitu belajar untuk mengaktualisasikan diri sebagai individu dengan kepribadiannya yang memiliki tanggung jawab pribadi, termasuk belajar untuk menyadari dan mewujudkan diri sendiri sebagai warga negara dan hamba Tuhan dengan segala konsekuensi dan tanggung jawab".

Pernyataan UNESCO tersebut mengintepretasikan bahwa arah pendidikan diselenggarakan bukan sekedar agar peserta didik paham materi pembelajaran, namun lebih pada aktualisasi diri, yakni menggunakan ilmu tersebut untuk kehidupan bermasyarakat dan pertanggungjawaban sebagai hamba Tuhan. Ditegaskan pula oleh [2] bahwa tujuan pendidikan bukanlah sekedar mempersiapkan peserta didik dengan seperangkat pengetahuan dan keterampilan agar bisa bekerja memenuhi kebutuhan dunia ekonomi, melainkan memiliki pengetahuan dan keterampilan sehingga bermanfaat bagi diri dan orang lain, sesama, dan masyarakatnya. Dalam rangka memajukan kualitas pendidikan tersebut, diperlukan peran pemerhati pendidikan untuk membuat inovasi pembelajaran. Salah satu upaya yang dapat ditempuh adalah dengan merancang pembelajaran menjadi terpadu dan mengintegrasikan bahan-bahan kajian menjadi keutuhan yang bermakna. Pembelajaran terpadu akan membantu siswa untuk dapat lebih baik dalam mengintegrasikan pengetahuan dan strategi belajarnya guna menghadapi kompleknya dunia [1]. Lebih lanjut, [3] turut mengungkapkan bahwa pembelajaran terpadu cocok dan dianjurkan untuk diaplikasikan pada semua jenjang pendidikan, mulai dari tingkat Sekolah Dasar (SD/MI) sampai dengan Sekolah Menengah Pertama (SMP/MTS). Dari beberapa ahli di atas, pembelajaran terpadu diharapkan mampu menjadi solusi permasalahan pendidikan di era global.

Dalam [4] mengemukakan bahwa diperlukannya pembelajaran terpadu di Sekolah Dasar (SD) 4 karena kemampuan berpikir dan kebutuhan psikologis yang khusus bagi pebelajar di SD. Tahap perkembangan kognifif anak SD yang masih dalam tahap operasional konkret. Semua itu agar pembelajaran di SD menjadi lebih efektif. Pembahasan pembelajaran terpadu terkait juga dengan bentuk kurikulum yang dipakai. Sekolah yang menggunakan sistem pembelajaran terpadu belum tentu memakai kurikulum terpadu juga. Pusat Kurikulum sendiri belum mempunyai konsep yang jelas tentang kurikulum terpadu yang selayaknya ada sebelum dilaksanakannya pembelajaran terpadu. Walaupun ada perbedaan definisi pembelajaran terpadu dan kurikulum terpadu, implementasi pembelajaran terpadu tentu diawali dengan suatu bentuk kurikulum.

Menurut [5] kurikulum terpadu didefinisikan sebagai bentuk kurikulum yang meniadakan batas-batas antara berbagai mata pelajaran dan menyajikan bahan pelajaran dalam bentuk unit atau keseluruhan. Menurut [6] bahwa pembelajaran terpadu merupakan sebuah proses pembelajaran dengan mengaitkan berbagai bidang studi. Aspek-aspek dari keterpaduaan dalam keterpaduan, yaitu: aspek pedagogi; sosiologi; dan psikologi. Keterpaduan dalam konsep pembelajaran terpadu tidak sekadar memadukan isi dan beberapa mata pelajaran, tetapi lebih luas lagi yaitu memadukan berbagai jenis keterampilan, sikap, atau kemampuan lainnya yang bertujuan agar pembelajaran lebih bermakna [7]. Sejalan dengan pendapat itu menurut [8] bahwa keterpaduan dapat dilakukan melalui keterpaduan dimana guru merencanakan suatu pembelajaran mata pelajaran untuk murid-muridnya dalam waktu bersamaan dengan berbagai mata pelajaran.Dengan demikian, dapat disimpulkan bahwa pembelajaran terpadu merupakan pembelajaran yang dikaitkan antar mata pelajaran atau topik yang relevan agar pembelajaran menjadi lebih bermakna.Menurut [9] berpendapat bahwa karakteristik perkembangan emosi siswa pada usia 6-8 tahun yaitu siswa telah dapat mengekspresikan reaksi terhadap orang lain, telah dapat mengontrol emosi, dan mulai mengerti mengenai benar dan salah. Untuk perkembangan siswa kelas awal ditunjukkan dengan kemampuannya dalam melakukan searasi, mengelompokkan obyek, berminat terhadap angka dan tulisan, meningkatnya kosa kata, dan senang berbicara.

Berdasarkan uraian diatas, maka untuk mengetahui problematika diatas, penulis meneliti dengan mengangkat judul "Implementasi Pembelajaran Terpadu di Sekolah Dasar Negeri Sarwiru". Adapun rumuasan masalah dari penelitian ini adalah sebagai berikut: 1. Bagaimana Implementasi Pembelajaran Terpadu di SD Negeri Sarwiru?, 2. Bagaimana kesulitan dalam mengimplementasikan Pembelajaran terpadu di SD Negeri Sarwiru?

Berdasarkan rumusan masalah diatas, bahwa tujuan dari penelitian ini adalah Untuk mengetahui Implementasi sistem pembelajaran terpadu di SD Negeri Sarwiru meliputi model pembelajaran, proses belajar mengajar dan evaluasi pembelajaran, 2. Untuk mengetahui kesulitan yang dialami dalam mengimpementaikan Pembelajaraan Terpadu.

\section{METODE PENELITIAN}

Pendekatan yang digunakan dalam penelitian ini adalah kualitatif dengan metode penelitian deskriptif. 
Sehingga analisis data yang digunakan dengan cara menelaah jawaban-jawaban yang didapat dari subjek penelitian. Jawaban-jawaban tersebut diorganisir dengan cara mengidentifikasi dan mengkategorikan sesuai dengan tujuan penelitian. Sehingga metode pengolahan data dilakukan dengan menguraikan data dalam bentuk kalimat teratur, runtun, logis, tidak tumpang tindih, dan efektif sehingga memudahkan pemahaman dan interpretasi data.

Lokasi yang akan diambil yaitu SD Negeri Sarwiru yang terletak di Dusun Sarwiru Kidul RT 02 RW 01 Desa Suriamedal Kecamatan Surian Kabupaten Sumedang. Pengumpulan data dalam penelitian ini dengan cara mewawancarai (Interview) 2 guru yang ada di SD Negeri Sarwiru. Intrumen penelitian yang digunakan adalah wawancara dimana pada penelitian ini berisi butir pertanyaan yang ditujukan kepada guru dalam implementasi pembelajaran terpadu di sekolah dasar.

Analisis data adalah proses pengolahan data dengan tujuan untuk menemukan informasi yang berguna yang dapat dijadikan dasar dalam pengambilan keputusan untuk solusi suatu permasalahan. Proses analisis ini meliputi kegiatan pengelompokkan data berdasarkan karakteristiknya, melakukan pembersihan data, mentransformasi data, membuat model data untuk menemukan informasi penting dari data tersebut. Analisis data pada penelitian ini dengan cara deskriptif. Dimana hasil wawancara disajikan dalam bentuk kata-kata

\section{HASIL DAN PEMBAHASAN}

Pembelajaran terpadu adalah pembelajaran yang terdiri dari beberapa mata pelajaran yang digabungkan dalam sebuah tema. Pada pelaksanaannya, pembelajaran terpadu dilakukan secara "ngaguluyur" yang artinya tidak memisahkan antara mata pelajaran yang satu dengan yang lainnya. Pembelajaran terpadu juga dapat memadukan satu materi dengan materi lainnya dalam 1 mata pelajaran yang sama. Adapun pada evaluasi nya tetap mengacu penilaian kognitif, afrktif, dan psikomotor dan nilai keterampilan anak yang ditujukan agar anak mampu menyesuaikan diri dengan masyarakat di era saat ini.

Konsep yang di terapkan dalam pembelajaran terpadu mengacu pada kurikulum 13 yang di terapkan saat ini. Sesuai dengan silabus dan RPP yang telah dibuat dan di rencanakan sebelum pembelajaran di laksanakan. Konsep yang merujuk pada pendekatan pembelajaran yang melibatkan beberapa mata pelajaran untuk memberikan pengalaman yang bermakna kepada siswa, sehingga siswa akan memahami konsep-konsep yang mereka pelajari melalui pengalaman secara langsung dan dapat menghubungkannya dengan konsep lain.

Pembelajaran tematik terpadu di SDN Sarwiru ini menggunakan model pembelajaran tematik jaring labalaba, dimana dalam pelaksaannya pembelajaran dilakukan dengan memadukan atau mengintegrasikan beberapa mata pelajaran dalam satu tema, kecuali di kelas atas, mata pelajaran matematika di laksanakan secara parsial atau terpisah tidak dipadukan dengan pelajaran matematika di laksanakan secara parsial atau terpisah tidak dipadukan dengan mata pelajaran lainnya. begitupun dengan mata pelajaran PJOK dan PAI, yang pada pelaksanaannnya terpisah dengan mata pelajaran seperti IPS, IPA, PPKn. SBdP, dan Bahasa Indonesia. Modelnya menggunakan spider webbed atau jaring laba-laba yaitu memadukan beberapa mata pelajaran dalam sebuah tema. Tema, subtema, dan pembelajaran sudah di tentukan oleh kurikulum yang saat ini dipakai. Sikap peserta didik lebih aktif dan antusias dalam mengikuti pembelajaran jika guru memang mengemas pembelajaran yang telah direncanakan tersebut dengan baik. Sikap tersebut muncul karena pada pembelajaran tematik ini memungkinkan siswa untuk learning by doing dan pembelajaran berpusat pada peserta didik yang memungkinkan peserta didik untuk aktif dan ikut andil dalam setiap proses pembelajaran. Adapun model tematik terhubung. Model ini digunakan sebagai alternatif dari masalah model jaring laba-laba yaitu adanya masalah keterpaduan antar mata pelajaran atau materi yang cenderung memaksakan untuk dipadukan.

Kendala yang di hadapi dalam penyusunan rencana pembelajaran terkadang ketika ada materi atau KD yang kurang sesuai untuk dipadukan atau terkesan "memaksakan" untuk dipadukan dengan materi lain dalam sebuah subtema, guru jadi bingung harus "menyambungkan" atau "memadukan" dengan cara apa.

Adapun solusinya dengan mengubah strategi pembelajaran, pembelajaran tematik terpadu biasanya menggabungkan beberapa mata pelajaran, jika terjadi ketidaksesuaian tersebut maka mengubahnya menjadi tematik 1 mata pelajaran saja dengan menggabungkan beberapa materi, jika masih tidak bisa dilakukan maka hanya fokus pada 1 materi saja dengan di dukung materi lainnya. Jika masih tidak dapat dilakukan dengan hal tersebut, maka biasanya mengambil langkah untuk mengubah model pembelajarannya menjadi model pembelajaran tematik terhubung.

Pembelajaran tematik bertujuan untuk mempersiapkan siswa hidup di masyarakat, jadi pembelejaran tematik disesuaikan dengan minat dan kebutuhan siswa. Oleh sebab itu pembelajaran tematik yang dilaksanakan sebisa mungkin disesuaikan dengan minat dan bakat siswa untuk persiapan beradaptasi di masyarakat.

Dalam tematik terpadu ini sebenarnya penilaian dikembalikan lagi pada mata pelajaran, sehingga terkadang cukup kesulitan karena penilaian dalam 1 mata pelajaran mencakup 3 aspek yaitu kognitif, afektif, dan psikomotor sedangkan pada pelaksanaannya pembelajaran dilakukan terpadu. Ada kalanya saat pembelajaran 
berlangsung harus sambil mengevaluasi/ observasi sikap siswa sambil mengamati langkah pembelajaran siswa. Rubrik penilaian di siapkan lebih awal pada RPP, untuk kriteria atau karakteristik penilaian yang kadang membutuhkan pemikiran kreatif, jika kesulitan maka solusinya adalah mencari referensi baik dari internet atau bertanya kepada rekan kerja untuk pemecahan masalah.

\subsection{Implementasi Pembelajaran Terpadu di SDN Sarwiru}

Implementasi pembelajaran terpadu kelas 2 di SDN Sarwiru Kabupaten Sumedang dari hasil wawancara guru memulainya dengan melakukan persiapan dengan membuat perangkat perencanaan pembelajaran terpadu. Perencanaan yang dibuat atau dituangkan ke dalam Rencana Pelaksanaan Pembelajaran (RPP). Persiapan guru berupa penetapan model, model yang digunakan yaitu model jaring laba-laba (Model Webbed). Dalam pelaksaannya pembelajaran dilakukan dengan memadukan atau mengintegrasikan beberapa mata pelajaran dalam satu tema, kecuali di kelas atas, mata pelajaran matematika di laksanakan secara parsial atau terpisah tidak dipadukan dengan mata pelajaran lainnya. begitupun dengan mata pelajaran PJOK dan PAI, yang pada pelaksanaannnya terpisah dengan mata pelajaran seperti IPS, IPA, PPKn, SBdP, dan Bahasa Indonesia. Hal in sejalan berdasarkan rumusan dari [10] Model webbed (Model Jaring Laba-laba) adalah pembelajaran terpadu yang menggunakan pendekatan tematik. Satu tema dijadikan rujukan untuk membahas materi sejumlah mata pelajaran yang sejalan atau memiliki keterkaitan ide dan tema. Selain menggunakan model webbed itu Guru di SDN Sarwiru juga menggunakan model keterhubungan, model ini digunakan sebagai alternatif dari masalah model jaring laba-laba yaitu adanya masalah keterpaduan antar mata pelajaran atau materi yang cenderung memaksakan untuk dipadukan. Berdasarkan rumusan dari [11] menyatakan bahwa model keterhubungan (connected) adalah model pembelajaran yang secara sengaja diusahakan untuk menghubungkan satu konsep dengan konsep lainnya, satu topik dengan topik lainnya, satu keterampilan dengan keterampilan lainnya, tugastugas yang dilakukan dalam satu hari dengan tugas-tugas yang dilakukan dihari berikutnya, bahkan ide-ide yang dipelajari dalam satu semester dengan ideide yang akan dipelajari pada semester semester berikutnya di dalam satu bidang studi.. di SDN Sarwiru ini merujuk pada pendekatan pembelajaran yang melibatkan beberapa mata pelajaran untuk memberikan pengalaman yang bermakna kepada peserta didik, sehingga peserta didik akan memahami konsep-konsep yang mereka pelajari melalui pengalaman secara langsung dan dapat menghubungkannya dengan konsep lain. Guru dengan berbagai pengalaman mengajar dan inovasi dalam melaksanakan pembelajaran sangat mendukung terlaksanakannya pembelajaran terpadu yang efektif dan efesien. Dalam hal ini, guru kelas 2 di SDN Sarwiru Kabupaten Sumedang memiliki pengalaman dalam mengikuti pelatihan yang selanjutnya diterapkan dalam pelaksanaan di sekolah sampai saat ini. Selain itu, guru juga melakukan inovasi dalam pembelajaran sehingga pembelajaran tidak akan monoton dan melakukan sesuatu yang baru dalam pembelajaran sehingga sikap peserta didik dalam menerima pembelajaran terpadu lebih aktif dan antusias dalam mengikuti pembelajaran terpadu. Sikap tersebut muncul karena pada pembelajaran terpadu ini memungkinkan peserta didik untuk learning by doing dan pembelajaran berpusat pada peserta didik yang memungkinkan peserta didik untuk aktif dan ikut andil dalam setiap proses pembelajaran.

\subsection{Hambatan Implementasi Pembelajaran Terpadu di SDN Sarwiru}

Dari hasil wawancara dalam pengimplemetasian pebelajaran terpadu di SDN Sarwiru Kabupaten Sumedang ini memiliki kesulitan yaitu terletak ketika mencari kaitan antara mata pelajaran satu dengan yang lain dalam satu tema dan kesulitan guru merancang pembelajaran tematik yang sangat padu. Hal ini terkait dengan ungkapan [12] bahwa, kurikulum terpadu dapat didefinisikan sebagai kurikulum yang semua elemennya terpadu baik melalui keterkaitan isi diantara mata pelajaran oleh pemilihan tema atau keterkaitan antar keterampilan oleh pemilihan tema atau topik. Namun dalam mencari kaitan antara mata pelajaran satu dengan yang lain guru masih merasa kesulitan. Ungkapan yang disampaikan Ibu Omah Komariah, mengenai kesulitan juga terletak pada dalam penyusunan RPP yaitu dalam evaluasinya, dalam menyusun evaluasi terkadang kesulitan menentukan karakteristik penilaian atau kriteria penilaian. Upaya guru untuk mengatasi kesulitan yang dialami dengan cara dengan mencari referensi melalui internet dan sharing dengan sesama guru tentang penyusunan evaluasi, selain itu juga mengkaji ulang Kompetensi Dasar (KD) pada materi yang di sampaikan agar mengetahui tujuan KD tersebut. Dengan diskusi, diharapkan dapat menemukan upaya untuk mengatasi masalah yang ditemukan. Guru juga diharapkan untuk terus membina diri dengan cara melakukan diskusi dengan guru lain dalam bentuk Team Teaching dan ikut serta dalam Kelompok Kerja Guru (KKG) guna memantapkan keterampilan dan keahlian merancang, melaksanakan dan mengevaluasi pembelajaran tematik terpadu.

\subsection{Perencanaan Pembelajaran Terpadu}

Berdasarkan hasil wawancara yang telah dilaksanakan, perencanaan yang digunakan guru sudah 
menggunakan konsep keterpaduan. Guru telah menyatukan beberapa mata pelajaran menjadi satu tema yang akan diajarkan pada peserta didik. Secara keseluruhan, perencanaan pembelajaran tematik di SDN Sarwiru telah sesuai dengan ketentuan yang berlaku.

\subsection{Pelaksanaan Pembelajaran Terpadu}

Pada pelaksanaan pembelajaran terpadu yang baik yaitu harus memenuhi beberapa karakteristik antara lain: memberikan pengalaman langsung, antar mata pelajaran tidak terpisah, menyajikan konsep dari berbagai mata pelajaran, menerapkan prinsip belajar sambil bermain, menekankan proses dari pada hasil dan bersifat fleksibel [13]. Berdasarkan hasil wawancara dengan guru SDN Sarwiru didapatkan hasil bahwa pada pelaksanaan susah menggunakan metode webbed atau jaring laba-laba. Yakni memadukan beberapa mata pelajaran menjadi satu tema. Adapun alternatif lain yang digunakan yaitu model tematik terhubung. Karena menurut guru yang telah diwawancarai terdapat kekurangan dari model jarring laba-laba adalah cenderung memaksakan dalam memadukan beberapa mata pelajaran yang dijadikan tema.

\subsection{Evaluasi Pembelajaran Terpadu}

Berdasarkan hasil wawancara, didapatkan hasil bahwa di SDN Sarwiru evaluasi yang digunakan sudah tematik. Penilaian yang dilakukan yaitu menilai aspek kognitif, aspek afektif, dan aspek psikomotor. Akan tetapi terdapat kendala yang dihadapi guru yaitu cukup kesulitan dalam menilai dalam 1 mata pelajaran mencakup 3 aspek yaitu kognitif, afektif, dan psikomotor sedangkan pada pelaksanaannya pembelajaran dilakukan terpadu. Pada evaluasi pembelajaran terpadu dilaksanakan dua penilaian yaitu penilaian proses dan penilaian hasil kegiatan [14].

\section{KESIMPULAN}

Berdasarkan hasil penelitian yang telah dilaksanakan, maka diperoleh beberapa kesimpulan sebagai berikut: 1. Implementasi sistem pembelajaran terpadu menggunakan model pembelajaran jaring laba-laba dan model connected, sehingga dapat memberikan pengalaman langsung oada siswa. 2. Hambatan yang dialami guru pada saat melaksanakan pembelajaran terpadu yaitu dalam penyusunan evaluasi sulit untuk menentukan karakteristik penilaian. Akan tetapi guru mencari solusi untuk hambatan yang dihadapi yaitu dengan mencari referensi melalui internet dan berbagi informasi sesama guru mengenai penyusunan evaluasi.

\section{DAFTAR PUSTAKA}

[1] A. Majid, Pembelajaran Tematik Terpadu. Bandung: Rosda, 2013.

[2] Zamroni, "Pendidikan Populis Berbasis Budaya". FIP Universitas Negeri Yogyakarta, 2013.

[3] Sugiyanto, Model-model Pembelajaran Inovatif. Surakarta: Yuma Pustaka, 2010.

[4] T. H. Subroto, Pembelajaran Terpadu. Jakarta: Pusat Penerbitan Universitas Terbuka, 2004.

[5] O. Hamalik, Kurikulum dan Pembelajaran. Jakarta: Bumi Aksara, 2005.

[6] U. Saud, Pembelajaran Terpadu Di Sekolah Dasar: Konsep dan Model-Model Implementasinya. Bandung: Alfabeta, 2005.

[7] Zaini, Strategi Pembelajaran Aktif. Yogyakarta: CSTD, 2004.

[8] S. Nasution, Berbagi Pendekatan Dalam Proses Belajar Mengajar. Jakarta: Bumi Aksara, 2004.

[9] Soemanto, Psikologi Pendidikan Landasan Kerja Pemimpin Pendidikan. Jakarta: Rineka Cipta, 2006.

[10] Trianto, Model Pembelajaran Terpadu. Jakarta: PT Bumi Aksara, 2012.

[11] A. Majid, Pembelajaran Tematik Terpadu. Bandung: PT Remaja Rosdakarya, 2017.

[12] W. Sundayana, Pembelajaran Berbasis Tema. Bandung: Erlangga, 2014.

[13] I. Hajar, Panduan Lengkap Kurikulum Tematik Untuk SD/MI. Yogyakarta: Diva Press, 2013.

[14] A. Prastowo, Panduan Kreatif Membuat Bahan Ajar Inovatif. Yogyakarta: Diva Press, 2012. 